\title{
Updates in Red Blood Cell and Platelet Transfusions in Preterm Neonates
}

\author{
Enrico Lopriore, MD, $\mathrm{PhD}^{1}$ \\ ${ }^{1}$ Division of Neonatology, Department of Pediatrics, Leiden \\ University Medical Center, Leiden, The Netherlands \\ Am J Perinatol 2019;36(suppl S2):S37-S40.
}

\begin{abstract}
Address for correspondence Enrico Lopriore, MD, PhD, Department of Pediatrics, Leiden University Medical Center, J6-S, Albinusdreef 2, 2333 ZA Leiden, The Netherlands (e-mail: e.lopriore@lumc.nl).
\end{abstract}

\begin{abstract}
Keywords

- anemia

- thrombocytopenia

- erythrocytes

- platelets

- transfusion

- neonates

Anemia and thrombocytopenia occur frequently in preterm neonates and the majority of them require at least one blood transfusion during the first few weeks of life. However, there is no international consensus on optimal transfusion management neither for red blood cell nor for platelet transfusions, resulting in large worldwide variations in transfusion practices between neonatal intensive care units. In the past decade, several studies performed in adults, infants as well as neonates showed that restrictive transfusion guidelines are just as safe as liberal guidelines. In fact, some studies even showed that liberal guidelines could be associated with an increased risk of morbidity and mortality, suggesting that too many transfusions may have a deleterious effect. In a recent randomized trial in preterm neonates with thrombocytopenia, the liberal transfusion group (receiving more platelet transfusions) had a significantly higher rate of death or major bleeding than the restrictive group (receiving less transfusions). In preterm neonates with anemia, the available evidence is also limited and controversial. Two large randomized controlled trials (ETTNO and TOP) are currently assessing the safety and effectiveness of liberal versus restrictive red blood cell transfusions. Results of these large two studies, including the long-term neurodevelopment outcome, are eagerly awaited. Until then, reduction of anemia of prematurity by implementation of effective preventive measures, such as delayed cord clamping and minimization of iatrogenic blood loss, remain of paramount importance.
\end{abstract}

Anemia and thrombocytopenia occur frequently in neonates admitted to neonatal intensive care units (NICUs), particularly in (very) preterm neonates. Management of these disorders has traditionally been based on the administration of blood products, either red blood cells (RBCs) or platelets to correct anemia and thrombocytopenia. Almost all very preterm neonates admitted to a NICU require at least one RBC transfusion during admission due to anemia, ${ }^{1}$ whereas approximately $10 \%$ of very preterm neonates receive platelet transfusions during their NICU stay (unpublished data from our center).

Although blood transfusions in the developed world are considered to be safe, long-term effects of adult donor blood products on the health and development of preterm neonates are not well known. In fact, the actual short-term benefits of transfusions in preterm neonates are not well known either. To date, transfusion guidelines are not based on solid scientific data but largely on expert opinion and dogmas. This lack of evidence and scientific data resulted in a lack of international consensus on transfusion indications and optimal thresholds. Consequently, transfusion practices between and within individual countries vary greatly. Nevertheless, an increasing number of studies are gradually shedding more light on this topic and report important new information on the safety and effectiveness of transfusions in neonates.

This review aims to provide an overview of the available evidence and current transfusion practices in neonates with anemia and thrombocytopenia and shortly discuss future developments. ISSN 0735-1631. 


\section{Neonatal Anemia and Red Blood Cell Transfusions}

Anemia in neonates can be physiological, but can also be caused by nonphysiological factors such perinatal or peripartum complications, clinical conditions such as sepsis and cardiorespiratory disease, and hemolytic disease of the fetus and newborn. However, one of the most important causes of anemia in very preterm neonates is iatrogenic blood loss due to frequent laboratory testing. Estimates of iatrogenic blood loss due to laboratory testing in the first month of life in preterm neonates admitted to a NICU may amount up to one-third of the total blood volume.

The main treatment modality for neonatal anemia is still based on the administration of RBC transfusions, but there is no international consensus regarding optimal hemoglobin thresholds for RBC transfusions in preterm neonates. Postulated hemoglobin thresholds for transfusions vary greatly between and within countries. In addition, the decision to transfuse is sometimes made based on clinical judgment of the caregiver, irrespective of national or local guidelines. Various national guidelines have been published in the past decade and are summarized in -Table $\mathbf{1}$.

To date, only a few randomized controlled trials (RCTs) compared different transfusion hemoglobin thresholds in very preterm neonates in regard to safety and effectiveness. As shown in the latest Cochrane review, ${ }^{2}$ no significant short-term nor long-term differences were found between liberal and restrictive RBC transfusion groups. However, these trials may have underpowered to detect a difference in the effect of transfusions on long-term neurodevelopmental outcome.

Two larger ongoing trials in this field may shed further light in the near future on the safety and effectiveness of liberal versus restrictive thresholds for RBC transfusions. The TOP trial (Transfusion of Prematures, NCT01702805) in the United States has included more than 1,800 preterm infants. A similar study, the ETTNO trial (Effects of Transfusion Thresholds on Neurocognitive Outcome of Extremely Low Birth Weight
Infants, NCT01393496), was performed in Germany and included more than 900 preterm neonates. In both studies, the primary outcome is death or significant neurodevelopment impairment in surviving infants determined at 2 years of age. The results of these two studies, including the long-term psychomotor assessment, are expected in the course of the coming year and will certainly increase our current knowledge and help improve international transfusion guidelines for RBC in neonates with anemia.

Although transfusions of RBC products are generally considered to be safe, short-term or long-term complications might be under recognized in the neonatal population, especially in (very) preterm neonates. Various studies in the adult population have identified several potential complications associated with transfusions, including transfusion-related lung injury and transfusion-associated circulatory overload. Whether these potential transfusion risks can also occur in the neonatal population remains unclear. Recently, several studies have suggested associations between RBC transfusions and intraventricular hemorrhage, necrotizing enterocolitis (the so-called TANEC, "transfusion-associated necrotizing enterocolitis"), retinopathy of prematurity, and iron overload. ${ }^{3-5}$ The pathophysiological explanations for these associations and the evidence of a possible causal relationship between transfusion and neonatal morbidities remain speculative.

Neonatologists should be aware of the current lack of evidence for optimal transfusion guidelines and the increasing reports on potential side effects. Until new evidence is gained, RBC transfusions in neonates with anemia should be used with caution. And, since prevention is often better than cure, preventing neonatal anemia should be a major aim.

Fortunately, prevention of neonatal anemia in preterm neonates can partly be achieved by implementing inexpensive measures such as (1) delayed cord clamping and (2) minimization of iatrogenic blood loss due to frequent laboratory testing. Both interventions may result in significant reduction of the need for transfusions in preterm neonates. Delaying cord clamping by at least 30 to 60 seconds after birth allows for a

Table 1 Overview of international guidelines and thresholds for RBC transfusions and platelet transfusions

\begin{tabular}{|c|c|c|c|c|c|c|c|c|}
\hline & \multicolumn{2}{|c|}{$\begin{array}{l}\text { British Committee } \\
\text { for Standards in } \\
\text { Haematology (2016) }\end{array}$} & \multicolumn{2}{|c|}{$\begin{array}{l}\text { Australian National Blood } \\
\text { Authority (2016) }\end{array}$} & \multicolumn{2}{|c|}{$\begin{array}{l}\text { Canadian Blood } \\
\text { Services (2017) }\end{array}$} & \multicolumn{2}{|c|}{$\begin{array}{l}\text { Dutch Guidelines } \\
\text { Quality council (2019) }\end{array}$} \\
\hline \multicolumn{9}{|c|}{ Neonatal anemia } \\
\hline $\begin{array}{l}\text { Postnatal } \\
\text { week }\end{array}$ & $\begin{array}{l}\text { Respiratory } \\
\text { support }\end{array}$ & $\begin{array}{l}\text { No respiratory } \\
\text { support }\end{array}$ & $\begin{array}{l}\text { Respiratory } \\
\text { support }\end{array}$ & $\begin{array}{l}\text { No respiratory } \\
\text { support }\end{array}$ & $\begin{array}{l}\text { Respiratory } \\
\text { support }\end{array}$ & $\begin{array}{l}\text { No respiratory } \\
\text { support }\end{array}$ & $\begin{array}{l}\text { Respiratory } \\
\text { support }\end{array}$ & $\begin{array}{l}\text { No respiratory } \\
\text { support }\end{array}$ \\
\hline Week 1 & $10-12 \mathrm{~g} / \mathrm{dL}$ & $10 \mathrm{~g} / \mathrm{dL}$ & $11-13 \mathrm{~g} / \mathrm{dL}$ & $10-12 \mathrm{~g} / \mathrm{dL}$ & $11.5 \mathrm{~g} / \mathrm{dL}$ & $10 \mathrm{~g} / \mathrm{dL}$ & $11.5 \mathrm{~g} / \mathrm{dL}$ & $10 \mathrm{~g} / \mathrm{dL}$ \\
\hline Week 2 & $9.5-10 \mathrm{~g} / \mathrm{dL}$ & $7.5 \mathrm{~g} / \mathrm{dL}$ & $10-12.5 \mathrm{~g} / \mathrm{dL}$ & $8.5-11 \mathrm{~g} / \mathrm{dL}$ & $10 \mathrm{~g} / \mathrm{dL}$ & $8.5 \mathrm{~g} / \mathrm{dL}$ & $10 \mathrm{~g} / \mathrm{dL}$ & $8.5 \mathrm{~g} / \mathrm{dL}$ \\
\hline Week $\geq 3$ & $8.5-10 \mathrm{~g} / \mathrm{dL}$ & $7.5 \mathrm{~g} / \mathrm{dL}$ & $8.5-11 \mathrm{~g} / \mathrm{dL}$ & $7-10 \mathrm{~g} / \mathrm{dL}$ & $8.5 \mathrm{~g} / \mathrm{dL}$ & $7.5 \mathrm{~g} / \mathrm{dL}$ & $8.5 \mathrm{~g} / \mathrm{dL}$ & $7.5 \mathrm{~g} / \mathrm{dL}$ \\
\hline \multicolumn{9}{|c|}{ Neonatal thrombocytopenia } \\
\hline $\begin{array}{l}\text { Prophylactic } \\
\text { in stable } \\
\text { infant }\end{array}$ & \multicolumn{2}{|l|}{$25 \times 10^{9} / \mathrm{L}$} & \multicolumn{2}{|l|}{$10-20 \times 10^{9} / \mathrm{L}$} & \multicolumn{2}{|l|}{$20 \times 10^{9} / \mathrm{L}$} & \multicolumn{2}{|l|}{$25 \times 10^{9} / \mathrm{L}$} \\
\hline $\begin{array}{l}\text { Bleeding or } \\
\text { invasive } \\
\text { procedure }\end{array}$ & \multicolumn{2}{|l|}{$50 \times 10^{9} / \mathrm{L}$} & \multicolumn{2}{|l|}{$50 \times 10^{9} / \mathrm{L}$} & \multicolumn{2}{|l|}{$50 \times 10^{9} / \mathrm{L}$} & \multicolumn{2}{|l|}{$50 \times 10^{9} / \mathrm{L}$} \\
\hline
\end{tabular}


prolonged placental transfusion and is now recommended in preterm and full-term neonates, as stated in a guideline by the World Health Organization. ${ }^{6}$ In preterm neonates, it is associated with higher hemoglobin levels after birth, fewer RBC transfusions, better circulatory stability, and possibly a lower risk for intraventricular hemorrhage and necrotizing enterocolitis compared with early cord clamping. ${ }^{7}$ Reducing iatrogenic blood loss can be achieved first by simply avoiding or minimizing often unnecessary laboratory testing. This can also be achieved by using microtechnique laboratory procedures which allow for smaller sampling volumes, the development of noninvasive monitoring methods, and consequent use of fetal blood from the placenta for baseline laboratory blood tests. ${ }^{8-10}$ Other supportive measures such as the administration of erythropoietin can also reduce the risk of anemia of prematurity and further investigations in the neonatal population are needed.

\section{Neonatal Thrombocytopenia and Platelet Transfusions}

Thrombocytopenia in neonates is defined as platelet count $<150 \times 10^{9} / \mathrm{L}$ and classified as early or late onset. Early-onset thrombocytopenia, which can be detected at birth or within 3 days after birth, is often caused by prenatal factors such as severe intrauterine growth restriction, maternal disease (preeclampsia), perinatal asphyxia, or fetal/neonatal alloimmune thrombocytopenia. Late-onset thrombocytopenia occurs after the first 3 days after birth and is then most commonly caused by bacterial sepsis, necrotizing enterocolitis, or thrombotic events associated with the use of central lines.

In analogy to neonatal anemia and RBC transfusions, the mainstay of treatment in neonatal thrombocytopenia is based on the administration of platelet transfusions. Similarly, the management of thrombocytopenia in neonates is mainly based on dogmas and beliefs rather than on solid scientific data. As a result, there is no international consensus on the optimal indications and thresholds for platelet transfusions in neonates, leading to wide worldwide variation in transfusion protocols. Several national guidelines on platelet transfusion thresholds are summarized in -Table 1.

Platelet transfusions in preterm neonates are usually given "prophylactically," i.e., indicated by a predefined platelet threshold, and only in a minority of cases "therapeutically" in case of an active major bleed. The aim of prophylactic platelet transfusions in preterm neonates is to prevent major bleedings such as intraventricular hemorrhages, lung bleeding, or gastrointestinal bleeding. However, the benefit of these prophylactic transfusions in nonbleeding neonates is unclear and controversial. ${ }^{11}$ There is no clear correlation between platelet cut-off values and individual bleeding risk.

A prospective observational study (Planet-1 study) showed that $81 \%$ of platelet transfusions in neonates are given prophylactically. ${ }^{12}$ of the 194 neonates in this study with platelet counts $<60 \times 109 / \mathrm{L}, 73 \%$ were reported to have minor hemorrhages, but only $9 \%$ developed severe hemorrhage. Of the 58 neonates with the most severe thrombocytopenia, with a platelet count $<20 \times 10^{9} / \mathrm{L}$, only $9 \%$ developed major hemorrhage. Until just recently, only one randomized trial was performed in preterm thrombocytopenic neonates comparing higher $\left(<150 \times 10^{9} / \mathrm{L}\right)$ versus a lower $\left(<50 \times 10^{9} / \mathrm{L}\right)$ platelet count threshold for prophylactic transfusion. The primary outcome in this RCT by Andrew et al was the incidence of intracranial hemorrhage, which did not significantly differ between the two treatment groups ( 26 vs. $28 \%, p=0.73$ ). ${ }^{13}$ In a recently published international randomized trial (Planet-2 study), 660 preterm neonates with severe thrombocytopenia were randomized to receive platelet transfusions at platelet count thresholds of $50 \times 109 / \mathrm{L}$ (liberal transfusion group) or $25 \times 109 / \mathrm{L}$ (restrictive transfusion group). ${ }^{14}$ Mortality rate of major bleeding within 28 days of randomization was significantly higher in the $<50 \times 10^{9} / \mathrm{L}$ group compared with the $<25 \times 10^{9} / \mathrm{L}$ group, respectively $26 \%$ (85/324) versus $19 \%$ (61/329) (odds ratio [OR]: $1.57 ; 95 \%$ confidence interval [CI]: $1.06-2.32 ; p=0.02)$. This study suggests that platelet transfusions in preterm neonates may cause more harm than previously thought. Restrictive platelet transfusion guidelines may thus be preferable compared with liberal transfusion guidelines. Surprisingly, the incidence of bronchopulmonary dysplasia (BPD), a secondary outcome in the Planet-2 study, was also significantly higher in the liberal transfusion group than in the restrictive group. The incidence of survival with BPD was 63\% (169/269) in the liberal transfusion group versus 54\% (153/281) in the restrictive group (OR: $1.54 ; 95 \% \mathrm{CI}: 1.03-2.30$ ). This important finding suggests that platelet products may have proinflammatory consequences and lead to organ damage. Although this trial clearly shows that guidelines should now be adapted toward a lower transfusion threshold (platelet counts $<25 \times 10^{9} / \mathrm{L}$ ), more research is needed to determine whether an even lower threshold should be used to guide platelet transfusion. Ideally, the indication for prophylactic platelet transfusions in preterm neonates should be based on an individual assessment of bleeding risk (incorporating various relevant clinical risk factors) rather than on an absolute platelet count level only. A reliable algorithm with a good predictive score quantifying the absolute risk of bleeding is already available for adult patients, and it could, in the future, prove to be useful in one of the most vulnerable group of patients with a high risk of bleeding: very preterm neonates.

\section{Conclusion}

To optimize transfusion guidelines, the results of ongoing RCTs need to be carefully evaluated and further research is needed in specific neonatal subpopulations to ascertain appropriate thresholds. The greatest advances in transfusion practice are preventive and supportive measures. Further reduction of iatrogenic phlebotomy, global implementation of delayed cord clamping, and timely recognition and treatment of underlying conditions such as infection may prevent a significant number of RBC transfusions. Until then, blood product transfusions in neonates should be used with caution and neonatologists should be aware that the evidence concerning the risks and benefits of transfusions in neonates 
is fairly limited. Further investigations and large welldesigned trials in preterm neonates are urgently needed.

\section{Conflict of Interest}

None declared.

\section{References}

1 von Lindern JS, Lopriore E. Management and prevention of neonatal anemia: current evidence and guidelines. Expert Rev Hematol 2014;7(02):195-202

2 Whyte R, Kirpalani H. Low versus high haemoglobin concentration threshold for blood transfusion for preventing morbidity and mortality in very low birth weight infants. Cochrane Database Syst Rev 2011;(11):CD000512

3 Fergusson DA, Hébert P, Hogan DL, et al. Effect of fresh red blood cell transfusions on clinical outcomes in premature, very lowbirth-weight infants: the ARIPI randomized trial. JAMA 2012;308 (14):1443-1451

4 Baer VL, Lambert DK, Henry E, Snow GL, Butler A, Christensen RD. Among very-low-birth-weight neonates is red blood cell transfusion an independent risk factor for subsequently developing a severe intraventricular hemorrhage? Transfusion 2011;51(06):1170-1178

5 Mohamed A, Shah PS. Transfusion associated necrotizing enterocolitis: a meta-analysis of observational data. Pediatrics 2012;129 (03):529-540

6 WHO. Delayed umbilical cord clamping for improved maternal and infant health and nutrition outcomes. Geneva, 2014. Available at: https://www.who.int/nutrition/publications/guidelines/ cord_clamping/en/. Accessed May 7, 2019
7 Rabe H, Diaz-Rossello JL, Duley L, Dowswell T. Effect of timing of umbilical cord clamping and other strategies to influence placental transfusion at preterm birth on maternal and infant outcomes. Cochrane Database Syst Rev 2012;(08): CD003248

8 Valentine SL, Bateman ST. Identifying factors to minimize phlebotomy-induced blood loss in the pediatric intensive care unit. Pediatr Crit Care Med 2012;13(01):22-27

9 Rosebraugh MR, Widness JA, Nalbant D, Veng-Pedersen P. A mathematical modeling approach to quantify the role of phlebotomy losses and need for transfusions in neonatal anemia. Transfusion 2013;53(06):1353-1360

10 Widness JA, Madan A, Grindeanu LA, Zimmerman MB, Wong DK, Stevenson DK. Reduction in red blood cell transfusions among preterm infants: results of a randomized trial with an in-line blood gas and chemistry monitor. Pediatrics 2005;115(05): 1299-1306

11 Fustolo-Gunnink SF, Huisman EJ, van der Bom JG, et al. Are thrombocytopenia and platelet transfusions associated with major bleeding in preterm neonates? A systematic review. Blood Rev 2018. Doi: 10.1016/j.blre.2018.10.001

12 Stanworth SJ, Clarke P, Watts T, et al; Platelets and Neonatal Transfusion Study Group. Prospective, observational study of outcomes in neonates with severe thrombocytopenia. Pediatrics 2009;124(05):e826-e834

13 Andrew M, Vegh P, Caco C, et al. A randomized, controlled trial of platelet transfusions in thrombocytopenic premature infants. J Pediatr 1993;123(02):285-291

14 Curley A, Stanworth SJ, Willoughby K, et al; PlaNeT2 MATISSE Collaborators. Randomized trial of platelet-transfusion thresholds in neonates. N Engl J Med 2019;380(03):242-251 